\title{
BMJ Global Health Generating statistics from health facility data: the state of routine health information systems in Eastern and Southern Africa
}

\author{
Abdoulaye Maïga (D) , ${ }^{1}$ Safia S Jiwani, ${ }^{1}$ Martin Kavao Mutua (D) , ${ }^{2}$ \\ Tyler Andrew Porth, ${ }^{3}$ Chelsea Maria Taylor, ${ }^{4}$ Gershim Asiki, ${ }^{2}$ Dessalegn Y Melesse, ${ }^{5}$ \\ Candy Day (1) , ${ }^{6}$ Kathleen L Strong, ${ }^{7}$ Cheikh Mbacké Faye (1) , \\ Kavitha Viswanathan, ${ }^{9}$ Kathryn Patricia O'Neill, ${ }^{9}$ Agbessi Amouzou (D) , ${ }^{1}$ \\ Bob S Pond, ${ }^{10}$ Ties Boerma (iD , ${ }^{11}$ Countdown to 2030 collaboration for Eastern \\ and Southern Africa
}

To cite: Maïga A, Jiwani SS, Mutua MK, et al. Generating statistics from health facility data: the state of routine health information systems in Eastern and Southern Africa. BMJ Global Health 2019;4:e01849. doi:10.1136/ bmjgh-2019-001849

Handling editor Seye Abimbola

- Additional material is published online only. To view please visit the journal online (http://dx.doi.org/10.1136/ bmjgh-2019-001849).

Received 17 July 2019 Revised 28 August 2019 Accepted 11 September 2019

Check for updates

\section{(C) Author(s) (or their} employer(s)) 2019. Re-use permitted under CC BY. Published by BMJ.

For numbered affiliations see end of article.

Correspondence to Dr Abdoulaye Maïga; amaiga1@jhu.edu

\section{ABSTRACT}

Health facility data are a critical source of local and continuous health statistics. Countries have introduced web-based information systems that facilitate data management, analysis, use and visualisation of health facility data. Working with teams of Ministry of Health and country public health institutions analysts from 14 countries in Eastern and Southern Africa, we explored data quality using national-level and subnational-level (mostly district) data for the period 2013-2017. The focus was on endline analysis where reported health facility and other data are compiled, assessed and adjusted for data quality, primarily to inform planning and assessments of progress and performance. The analyses showed that although completeness of reporting was generally high, there were persistent data quality issues that were common across the 14 countries, especially at the subnational level. These included the presence of extreme outliers, lack of consistency of the reported data over time and between indicators (such as vaccination and antenatal care), and challenges related to projected target populations, which are used as denominators in the computation of coverage statistics. Continuous efforts to improve recording and reporting of events by health facilities, systematic examination and reporting of data quality issues, feedback and communication mechanisms between programme managers, care providers and data officers, and transparent corrections and adjustments will be critical to improve the quality of health statistics generated from health facility data.

\section{INTRODUCTION}

Routine health information systems (RHIS), based on data reported by health facilities, are an important source of health statistics that feature prominently in national and subnational health plans and programme. ${ }^{1-3}$ Multiple indicators generated by the RHIS

\section{Summary box}

Routine health information systems are a potential source of data to generate health statistics and indicators to track national and subnational progress towards universal health coverage and to inform planning and assessments of progress and performance.

- The introduction of web-based digital platforms (DHIS2) was a notable development leading to better standardisation of data collection and to gradual improvements in data quality, but there are persistent data quality issues.

- Using population projections from National Statistical Offices for target populations often leads to improbable coverage statistics, but several countries are exploring alternative methods.

- Endline analysis is an important component of continuous efforts to improve facility-based statistics, including systematic ways to examine and present data quality issues and use of transparent adjustment procedures.

- National analysts in the Ministry of Health, public health institutions and national statistical offices need to have access to an optimal set of tools and skills to analyse and synthesise health facility data and produce the best possible statistics with well-documented audit trails.

data can be used to track national and subnational progress towards universal health coverage, often in combination with household survey and other data. Scorecards and dashboards are increasingly popular tools to visualise the statistics based on health facility data, aiming to facilitate the interpretation, communication and use of data. ${ }^{4}$ 
Countries and development partners have been investing in the improvement of the data generation and use through the RHIS. ${ }^{45}$ A notable development is the introduction of the District Health Information System (DHIS), which is an open-source software platform for reporting, quality checks, visualisation, analysis and dissemination of data for all health programme. ${ }^{6}$ From 2010 onwards, an increasing number of countries began to introduce the web-based DHIS2 platform, and today many countries are using this electronic platform. ${ }^{7}$

Common RHIS data-based indicators include causes of death and morbidity patterns among persons using health services, health service utilisation and efficiency indicators, as well as a range of program-specific indicators on the coverage of interventions. ${ }^{8}$ Several programmes such as immunisation and HIV have been relying extensively on facility data-based coverage statistics for country and global monitoring. ${ }^{9-11}$

Studies have shown multiple issues regarding the quality of data generated by health facilities that affect the credibility and utility of RHIS-based statistics at local and national levels. ${ }^{12-18}$ The main challenges are associated with incomplete and inaccurate reporting of events, as well as problems with defining accurate denominators (ie, target populations) for the computation of coverage statistics.

This paper describes the situation in 14 countries in Eastern and Southern Africa in 2017, based on an analysis project involving teams of Ministry of Health and country public health institutions analysts, organised by the African Population Health Research Centre, Countdown to 2030 for Women's, Children's and Adolescents' Health, WHO and UNICEF. The focus was on 'endline' analysis where all relevant health facility data are compiled and systematically assessed, including assessment and adjustment for incomplete reporting, detection and correction of extreme outliers, assessment and revision of denominators, comparison with survey-based results and computation of statistics based on the adjusted data set. These analyses were done in MS Excel 2013, using data exported from the DHIS2 country databases.

\section{COUNTRY CONTEXTS}

The 14 countries produced data for 937 subnational units (primarily districts) with an average population size of 274278 per unit, ranging from less than 100000 in districts in Eritrea, Botswana and Namibia, to over one million in Kenya's counties and South Sudan's states (table 1). All countries were using the RHIS data for statistical reporting. In 2017, the RHIS data were underpinning annual health statistical reports (10 countries), health system performance assessment reports (7), national health statistical profiles (8) and district health statistical profiles (10). Mozambique and Zambia produced all four outputs.

Routine service data are collected on paper by most health facilities and reported to the district on a monthly

Table 1 General characteristics and reporting completeness, national (\%) and subnational units, 2017

\begin{tabular}{|c|c|c|c|c|c|c|c|}
\hline Country & $\begin{array}{l}\text { Population } \\
\text { (2017) }\end{array}$ & $\begin{array}{l}\text { Type of } \\
\text { administrative } \\
\text { unit }\end{array}$ & $\begin{array}{l}\text { Number of } \\
\text { subnational } \\
\text { units }\end{array}$ & $\begin{array}{l}\text { Average } \\
\text { population } \\
\text { per unit }\end{array}$ & $\begin{array}{l}\text { Number } \\
\text { of health } \\
\text { facilities }\end{array}$ & $\begin{array}{l}\text { Reporting } \\
\text { rate }\end{array}$ & $\begin{array}{l}\text { Per cent of } \\
\text { subnational } \\
\text { units with } \\
\geq 90 \% \\
\text { reporting } \\
\text { rates }\end{array}$ \\
\hline Botswana & 2218739 & District & 27 & 82176 & 1702 & 69 & 22 \\
\hline Burundi & 9978120 & District & 46 & 216916 & 1253 & 97 & 90 \\
\hline Eritrea & 3781759 & District & 58 & 65203 & 398 & 96 & 92 \\
\hline Kenya & 48576374 & County & 47 & 1033540 & 10753 & 82 & 32 \\
\hline Lesotho & 1941941 & District & 10 & 194194 & 290 & 76 & 45 \\
\hline Malawi & 17373185 & District & 29 & 599075 & 719 & 86 & 66 \\
\hline Mozambique & 26863901 & District & 161 & 166857 & 1886 & 94 & 74 \\
\hline Namibia & 2348872 & District & 35 & 67111 & 407 & 71 & 41 \\
\hline Rwanda & 11809295 & District & 30 & 393643 & 818 & 96 & 88 \\
\hline South Sudan & 11837437 & State & 10 & 1183744 & 1597 & 49 & 0 \\
\hline Tanzania* & 52619314 & Council & 184 & 285975 & 7403 & 99 & 98 \\
\hline Uganda & 37741300 & District & 128 & 294854 & 7056 & 99 & 95 \\
\hline Zambia & 16180840 & District & 109 & 148448 & 2996 & 96 & 88 \\
\hline Zimbabwe & 13727493 & District & 63 & 217897 & 1778 & 99 & 100 \\
\hline Total/median** & 256998570 & & 937 & 274278 & 1702 & 95 & 81 \\
\hline
\end{tabular}

* 2018, reference year for Tanzania.

** Values in bold are median values 
basis. The paper-based facility reports are entered into a computer in the districts and are accessible at the district and national levels. Among the 14 countries, 13 use DHIS2 for most data and programmes, while South Sudan uses DHIS V.1. In 8 of the 14 countries, DHIS has been operational for at least 5 years.

\section{COMPLETENESS OF REPORTING}

The reporting rates are based on the number of reports received divided by the expected number of reports from all listed facilities in the RHIS (master facility list), including public, non-government organisation (NGO) and private-for-profit facilities. Variation in reporting rates between districts or over time will affect performance and trend analysis of coverage and other indicators. Most countries ignore reporting rates in the analysis of differences or trends in indicators, which means that it is assumed that non-reporting facilities are not providing any services. If reporting completeness is well over $90 \%$, the impact of this assumption is limited. Some country analyses, however, adjusted for incomplete reporting, using assumptions about level of activity in non-reporting facilities compared with those that reported. ${ }^{19}$ These adjustments to the data set need to be made in a transparent manner, creating an adjusted data set without modifying the underlying reported data.

Reporting rates have improved to high levels in most countries, which was corroborated by other studies (table 1). ${ }^{20}{ }^{21} \mathrm{~A}$ few countries use a harmonised monthly reporting form that includes all health services, but most rely on a separate set of reporting forms for each service. In case of multiple forms, we computed the average of the reporting rate for outpatient department (OPD) services, antenatal care; institutional delivery and immunisation services. Very low reporting rates were observed in South Sudan (49\%), often related to armed conflict, but the overall picture shows high reporting rates with eight countries exceeding $90 \%$.

\section{ACCURACY OF REPORTED HEALTH FACILITY DATA}

The accuracy of the data (the extent to which the data reflect the true numbers) can be assessed through endline analyses and facility assessments with data verification. The latter method relies on facility visits and record reviews to compare reported data with source documents within the facility and is discussed elsewhere. ${ }^{10}$ DHIS2 has now incorporated a WHO data quality module that can be used to identify outliers and assess internal and external consistency. ${ }^{22}$ By 2018, 6 of the 14 countries were using this tool within DHIS2.

The internal consistency of the health facility data is examined with three data quality metrics: presence of major outliers, variation for selected indicators over time and consistency between interventions. Major outliers for monthly aggregated data should be detected and corrected at the early stages of facility and district reporting. At the endline analysis stage, a final check for any extreme outliers is important as the impact on the results can be very large. Errors should be corrected with a clear audit trail (ie, a record of what has been changed). To confirm whether extreme outliers are in fact errors, external factors will need to be considered such as prolonged stock-outs (eg, vaccines), the seasonality of diseases (eg, malaria) or population migration (eg, conflicts, refugees). In the country data sets for the most recent year of the 14 countries, extreme outliers were identified using a modified Z-score, using 3.5 SD from the median based on the previous 3 years as threshold. ${ }^{22}{ }^{23}$ In general, extreme outliers were rare (country median 6\%), but cannot be ignored (table 2).

There is usually only limited year-to-year variation in the reported numbers of interventions for, for example, first antenatal care visit (ANC1), first dose of diphtheria-pertussis-tetanus vaccine (DPT1) and OPD visits. We expect a modest annual increase in the number of people receiving services due to population growth (about $1.4 \%$ per year in Southern Africa and 2.8\% per year in Eastern Africa) and potential improvements in service coverage. ${ }^{24}$ To assess year-to-year variation, we used the modified Z-score with $2 \mathrm{SD}$ from the median for the three preceding years to identify potential inconsistencies. There was considerable variation for the national and district levels in several countries (table 2). The median percentage of districts with no outliers was $61 \%$ (IQR: 22\%).

Internal consistency of interventions was assessed between ANC1 and DPT1 vaccination (recommended at 6 weeks of age) and between the first and the third doses of DPT vaccine. The metric is computed as the absolute difference in the ratio of expected numbers of ANC1 and DPT1 from the ratio of reported numbers of ANC1 and DPT1. The expected ratio is obtained from the population coverage rates in a recent household survey such as Demographic and Health Survey or Multiple Indicator Cluster Survey. Good internal consistency is defined as a small difference $(\leq 5 \%)$ between reported numbers of ANC1 and pentavalent1/DPT1. The accuracy of reported numbers of DPT1 and DPT3 was assessed similarly. Table 2 presents the results of the assessment, showing substantial quality issues for almost all countries, especially for consistency between ANC1 and DPT1. Mozambique presents an extreme outlier $(179 \%)$, which is due to major over-reporting of ANC1, as the expected number of births is closer to the DPT1 vaccinations. That must be due to a systematic error in the system. Online supplementary annex 1 shows the ratio of the reported number of ANC1 by the reported number of DPT1 over time and by country.

\section{TARGET POPULATIONS}

The national population census provides data on the population by age and sex, which are projected using assumptions about fertility, mortality and migration. The longer ago the census, the less accurate the projections. In 2018, the median year of the most recent census used for the population projections in the 14 countries was 
Table 2 Health facility data quality of reported event data, 2017: extreme outliers, consistency over time and internal consistency between interventions

\begin{tabular}{|c|c|c|c|c|c|c|c|}
\hline \multirow[b]{2}{*}{ Country } & \multicolumn{3}{|c|}{$\begin{array}{l}\text { Extreme outliers for ANC, DPT and } \\
\text { OPD }\end{array}$} & \multirow{2}{*}{$\begin{array}{l}\begin{array}{l}\text { Consistency } \\
\text { over time* }\end{array} \\
\% \text { of units with } \\
\text { consistent time } \\
\text { trends }\end{array}$} & \multicolumn{3}{|c|}{ Internal consistency between interventions $\dagger$} \\
\hline & $\begin{array}{l}\% \text { of } \\
\text { national } \\
\text { values } \\
\text { that are } \\
\text { outliers } \ddagger\end{array}$ & $\begin{array}{l}\% \text { of units } \\
\text { with no } \\
\text { outliers (last } \\
12 \text { months) } ¥\end{array}$ & $\begin{array}{l}\% \text { of units } \\
\text { with no } \\
\text { outliers } \\
\text { (last } 3 \\
\text { years)§ }\end{array}$ & & $\begin{array}{l}\text { ANC1-DPT1: } \\
\% \text { difference } \\
\text { from } \\
\text { expected } \\
\text { ratio }\end{array}$ & $\begin{array}{l}\text { DPT1-DPT3: } \\
\% \text { difference } \\
\text { from } \\
\text { expected } \\
\text { ratio }\end{array}$ & $\begin{array}{l}\text { \% of units } \\
\text { with good } \\
\text { consistency for } \\
\text { both indicator } \\
\text { pairs }\end{array}$ \\
\hline & (a) & (b) & (c) & (d) & (e) & (f) & (g) \\
\hline Botswana & 6 & 57 & 75 & 43 & - & - & - \\
\hline Burundi & 5 & 59 & 50 & 43 & 17 & 2 & 47 \\
\hline Eritrea & 6 & 52 & 65 & 40 & 28 & 7 & 16 \\
\hline Kenya & 3 & 81 & 42 & 37 & 1 & 1 & 57 \\
\hline Lesotho & 6 & 57 & 34 & 47 & 5 & 14 & 25 \\
\hline Malawi & 10 & 62 & 60 & 40 & 76 & 6 & 35 \\
\hline Mozambique & 7 & 48 & - & - & 179 & 11 & 2 \\
\hline Namibia & 8 & 46 & 62 & 23 & 7 & 4 & 37 \\
\hline Rwanda & 7 & 51 & 77 & 40 & 7 & 0 & 63 \\
\hline South Sudan & 7 & 53 & 80 & 33 & 67 & 57 & - \\
\hline Tanzania & 6 & 54 & 47 & 43 & 5 & 1 & 38 \\
\hline Uganda & 6 & 58 & - & - & 8 & 12 & 18 \\
\hline Zambia & 7 & 52 & 37 & 43 & 3 & 6 & 40 \\
\hline Zimbabwe & 5 & 60 & 63 & 37 & 5 & 3 & 5 \\
\hline Median & 6 & 55 & 61 & 40 & 7 & 6 & 36 \\
\hline IQR & 1 & 6 & 22 & 7 & 22 & 9 & 24 \\
\hline
\end{tabular}

(a) Average percentage of outliers for ANC1, DPT3 and OPD; (b) average percentage for ANC1, DPT3 and OPD; (c) average percentage for ANC1, DPT1 and OPD.

*Good consistency over time defined as modified z-score lower than 1.

†Percentage difference between routinely reported ratio and survey: values were classified as good $(<5)$, different $(5-15)$ or very different (>15).

$\ddagger$ Outliers defined as modified z-score greater than 3.5; units are second-level administrative divisions in each country (district, county, etc). §Outliers defined as modified z-score greater than 2; units are administrative divisions in each country (district, county, etc).

ANC, antenatal care; DPT, diphtheria-pertussis-tetanus; OPD, outpatient department.

2009 (table 3). Only Uganda had projections based on a census conducted less than 5 years ago. Two countries had conducted censuses from 2016 to 2017 (Lesotho, Mozambique), but population projections were not yet available by November 2018 .

Population projections were provided by National Statistical Offices. Based on our assessment of the population growth rates and parameters used to compute the target populations, a constant population growth rate for all years was used in half of the 14 countries (Burundi, Eritrea, Malawi, Rwanda, South Sudan, Tanzania and Zimbabwe). The crude birth rate (CBR) is a critical input for the RHIS, but very few countries used results on birth rates from recent national surveys, and none used subnational birth rates to estimate target populations.

The population projections from National Statistical Offices are the standard tool for obtaining target populations, but additional methods are needed to supplement those estimates for health statistical analyses. Censuses may have inaccuracies (such as an undercount of some areas) and projections can deviate substantially from reality, especially if there is substantial migration.

Frequent changes to administrative boundaries (increasing the number of districts and provinces/ regions) were common, further complicating population projections. In addition, census-based projections can be a challenge since people may seek care from health facilities outside their district of residence. This has also been referred to as numerator/denominator mismatch. ${ }^{9121525}$ The result can be that some districts have coverage that is significantly greater than $100 \%$ while other districts and health facilities have very low coverage when census projections are used to estimate denominators.

To explore the consistency of denominators, we compared the results from four methods to estimate the number of live births at the national level: the number of births projected by the National Bureau of Statistics, the number of births computed from the total population projections by the National Bureau of Statistics and the CBR from the most recent household survey, the number 
Table 3 Most recent census and coverage rates of ANC1, BCG and DPT1 in most recent household surveys (\%)

\begin{tabular}{llllll}
\hline Country & Year of last census & Survey & ANC1 $^{*}$ & BCG $^{*}$ & DPT1 $^{*}$ \\
\hline Botswana & 2011 & MICS-2000 & 92.5 & 97.9 & 95.6 \\
\hline Burundi & 2008 & DHS-2016 & 99.3 & 97.7 & 99.2 \\
\hline Eritrea & None & DHS-2002 & 71.6 & 91.4 & 90.6 \\
\hline Eswatini & $2017 \dagger$ & MICS-2014 & 98.7 & 98.4 & 96.4 \\
\hline Kenya & 2009 & DHS-2014 & 95.3 & 96.7 & 97.5 \\
\hline Lesotho & $2016 \dagger$ & DHS-2014 & 95.0 & 98.0 & 98.3 \\
\hline Malawi & 2008 & DHS-2015 & 94.9 & 97.6 & 97.4 \\
\hline Mozambique & $2017 \dagger$ & DHS-2011 & 90.7 & 91.1 & 91.3 \\
\hline Namibia & 2001 & DHS-2013 & 96.6 & 94.2 & 92.7 \\
\hline Rwanda & 2012 & DHS-2015 & 99.1 & 98.9 & 99.1 \\
\hline South Africa & 1996 & DHS-2016 & 93.9 & 92.5 & 91.2 \\
\hline South Sudan & 2008 & MICS-2010 & 42.8 & 34.4 & 28.1 \\
\hline Tanzania & 2012 & DHS-2015 & 97.9 & 96.0 & 97.0 \\
\hline Uganda & 2014 & DHS-2016 & 97.5 & 96.3 & 94.9 \\
\hline Zambia & 2010 & DHS-2013 & 95.4 & 94.9 & 95.9 \\
\hline Zimbabwe & 2012 & DHS-2015 & 92.0 & 89.9 & 89.5 \\
\hline Median & 2009 & & 95.3 & 96.0 & 95.9 \\
\hline
\end{tabular}

${ }^{*}$ Coverage statistics from last survey.

†Projection data not yet available by mid-2018.

ANC, antenatal care; BCG, Bacille de Calmette and Guerin; DHS, Demographic and Health Survey; DPT, diphtheria-pertussis-tetanus; MICS, Multiple Indicator Cluster Survey.

of births derived from the reported number of DPT1 vaccinations reported and from the reported number of first antenatal visit through the RHIS, both adjusted for incomplete reporting and for non-use of services. The latter two methods use the facility data for high-coverage interventions such as ANC1 visit, Bacille de Calmette and Guerin (BCG) or DPT1 vaccination to obtain estimates of the target population size. ${ }^{19}$ The accuracy of these alternative denominators depends primarily on the quality of reporting by the health facilities. In addition to the data quality assessments presented in this paper, external validation of coverage estimates obtained with facility data-based denominators with survey-based statistics, for instance third dose of DPT1 vaccine, four antenatal visits or institutional delivery, provides critical information on the quality of reporting in the RHIS. Data quality and primarily over-reporting of events such as vaccinations are particular concern, in some cases, if there are incentives for vaccinating children. ${ }^{26}$ Studies in Kenya and Tanzania are examples of the use of facility data-derived denominators for coverage estimates. ${ }^{19} 27$

Figure 1 shows substantial differences between the methods of estimating live births at the national level in selected countries, illustrating the challenge of obtaining accurate denominators for facility data-based analysis. This challenge is magnified if we consider district-level denominators. The projections, whether official projections or estimates obtained from recent CBR data, provide denominators that lead to problematic results. Overall, one-third of districts (median 33\%, IQR=48\%) and nearly half of countries (median 46\%, IQR=25\%) had DPT1 coverage rates exceeding $100 \%$ based on the birth projections and the CBR method, respectively (table 4). These results suggest that the district target populations may be too small or that over-reporting of vaccinations may occur. Similarly, a high proportion of subnational units have unlikely low coverage rates, even though DPT1 coverage rates are expected to be high almost everywhere according to survey data. Possible explanations are overestimation of target populations, under-reporting of events or numerator/ denominator mismatches.

The choice of the denominator is based on multiple arguments. If the differences between service-based and census-based estimates of target populations are small, it is best to use the census-based projections, particularly for national and region/provincial level. However, national consistency does not necessarily mean that these denominators work well for all districts. Ultimately, the choice needs to be made based on an individual district analysis that may lead to the identification of groups of districts for which the population projections do not perform as well as target populations. Kenya and Rwanda provided examples of the use of facility reports (DPT1 and BCG, respectively) in endline analyses to improve the estimation of target populations and coverage rates.

\section{ANALYSIS}

A clean health facility data set should form the basis for analyses that are presented in annual reports and other formats to inform monitoring of progress and annual 




Figure 1 Estimated number of live births (denominators) for coverage statistics, projections and facility data, selected countries, national level, 2017. ANC, antenatal care; CBR, crude birth rate; DPT, diphtheria-pertussis-tetanus.

reviews, and evidence-based policy and programme planning. Several countries rank districts according to coverage rates or indexes of performance (eg, Uganda). Further analyses may include quantifying district-level estimates of populations reached and not reached with specific interventions and comparisons of district health outputs with health system and other inputs. ${ }^{11} 2728$ In addition, the combination of analyses and presentation

Table 4 Percentage of districts with coverage over $100 \%$ and of districts with coverage at least $15 \%$ lower than national level, using official projections of population and births by district, 2017

\begin{tabular}{|c|c|c|c|c|c|c|c|c|}
\hline \multirow[b]{2}{*}{ Country } & \multicolumn{2}{|c|}{$\begin{array}{l}\text { ANC1 coverage }>100 \% \\
\text { based on }\end{array}$} & \multicolumn{2}{|c|}{$\begin{array}{l}\text { ANC1 coverage } \\
\text { at least } 15 \% \\
\text { lower based on }\end{array}$} & \multicolumn{2}{|c|}{$\begin{array}{l}\text { DPT1 coverage }>100 \% \\
\text { based on }\end{array}$} & \multicolumn{2}{|c|}{$\begin{array}{l}\text { DPT1 coverage } \\
\text { at least } 15 \% \\
\text { lower based on }\end{array}$} \\
\hline & Births & CBR & Births & CBR & Births & CBR & Births & CBR \\
\hline Botswana & - & - & - & - & - & - & - & - \\
\hline Burundi & 83 & 70 & 15 & 39 & 41 & 43 & 15 & 22 \\
\hline Eritrea & 95 & 12 & 28 & 33 & 95 & 9 & 25 & 24 \\
\hline Kenya & 15 & 34 & 19 & 21 & 17 & 43 & 11 & 17 \\
\hline Lesotho & 20 & 40 & 30 & 20 & 0 & 0 & 10 & 20 \\
\hline Malawi & 0 & 0 & 0 & 0 & 7 & 45 & 28 & 28 \\
\hline Mozambique & 7 & 91 & 21 & 51 & 2 & 63 & 0 & 35 \\
\hline Namibia & - & 21 & - & 47 & - & 59 & - & 47 \\
\hline Rwanda & 80 & 23 & 13 & 23 & 93 & 37 & 7 & 20 \\
\hline South Sudan & 100 & - & 50 & - & 100 & - & 50 & - \\
\hline Tanzania & 55 & 71 & 58 & 32 & 53 & 73 & 15 & 21 \\
\hline Uganda & 15 & 66 & 19 & 25 & 25 & 79 & 19 & 28 \\
\hline Zambia & 30 & 76 & 23 & 28 & 30 & 73 & 29 & 33 \\
\hline Zimbabwe & 6 & 44 & 16 & 10 & 37 & 48 & 40 & 41 \\
\hline Median & 25 & 42 & 20 & 27 & 33 & 46 & 17 & 26 \\
\hline IQR & 68 & 47 & 13 & 13 & 48 & 25 & 18 & 13 \\
\hline
\end{tabular}

ANC, antenatal care; CBR, crude birth rate; DPT, diphtheria-pertussis-tetanus. 
of statistics from survey and facility reports enables a more complete interpretation of facility data-based statistics, but was not done on a regular basis in any of the 14 countries.

In future, analyses using geospatial or other advanced methods could help generate predicted values that could serve as a method to assess the plausibility and quality of statistics that are generated from health facility data, especially at the district level. ${ }^{11} 1329$

\section{CONCLUSION}

The assessment of health facility data from 14 countries of the Eastern and Southern Africa region showed the potential of such data for regular (sub) national health statistics. The introduction of web-based digital platforms that facilitate the analysis, use and visualisation of health facility data at the district level appears to lead to gradual improvements in data quality, especially completeness of reporting, and enables a systematic approach of data quality assessment and analysis. Yet, major gaps remain. First, as shown with the data from the 14 countries, there are major data quality problems that need to be addressed in the coming years, including improvement of estimation of target populations. Several studies have described the problems and implemented ways to improve the quality of routine data with varying success, including training of health workers, strengthening of feedback, introduction of case-based electronic management systems, data verification surveys and other interventions. ${ }^{5} 14$ 30-32

Second, in most countries, use of facility data is restricted to a limited number of individuals. Five countries indicated that they provide a wider public access based on an access password on request. The access to health data facility, information distribution and promotion of culture of information are critical for improving health information systems and health status more broadly. Facility data are promising sources of statistics for evidence-based decision making, planning and advocacy. ${ }^{33}$ Less restrictive and systematic access to data also stands for transparency about data processing and quality.

Third, data quality assessment and computation of credible statistics from health facility data are not straightforward. Technology has advanced much faster than data quality improvements. Currently, country capacities to deal with health facility data, carry out data quality assessment and adjustments and produce credible statistics are still limited. National analysts in the Ministry of Health, public health institutions and national statistical offices need to have access to an optimal set of tools and skills to analyse and synthesise health facility data and produce the best possible statistics with well-documented audit trails.

The use of data from RHIS, to improve health system performance or to make evidence-based decisions, remains suboptimal in many developing countries in Africa and Asia. ${ }^{35}$ The Performance of Routine Information
System Management (PRISM) framework describes the factors linked to access, quality and use of data and the lack of 'information culture' in those countries. ${ }^{33}{ }^{35}$ RHIS is defined as a complex system in the PRISM framework, and its improvement requires to bring together and take into account the role and relationships between the technical, organisational or environmental and behavioural factors to improve routine health data quality and use of health information in order to strengthen the health system and population health status as an ultimate goal. ${ }^{33}$ There are improvements in the data culture as evidenced by countries' interest in scorecards and the use of WHO data quality module incorporated in DHIS2.

The technological advances provide a major opportunity to further strengthen data quality and analyses of health facility data at local and national levels in the coming years. Improved statistics from health facility data are a critical step towards evidence-based planning and targeting of programme on the road to universal health coverage of essential interventions.

\section{Author affiliations}

${ }^{1}$ International Health, Johns Hopkins University Bloomberg School of Public Health, Baltimore, Maryland, USA

${ }^{2}$ Department of Research, African Population and Health Research Center, Nairobi, Kenya

${ }^{3}$ Division of Data, Research and Policy, Data and Analytics Section, UNICEF, New York City, New York, USA

${ }^{4}$ Data Analytics and Delivery, World Health Organization, Geneva, Switzerland

${ }^{5}$ Department of Community Health Sciences, University of Manitoba, Winnipeg, Manitoba, Canada

${ }^{6}$ Health System Trust, Westville, South Africa

${ }^{7}$ Maternal, Newborn, Child and Adolescent Health Department, World Health Organization, Geneva, Switzerland

${ }^{8}$ West Africa Regional Office, African Population and Health Research Center, Nairobi, Kenya

${ }^{9}$ Information Evidence and Research, World Health Organization, Geneva, Switzerland

${ }^{10}$ Independent Consultant, Portland, Oregon, USA

${ }^{11}$ Centre for Global Public Health, University of Manitoba, Winnipeg, Manitoba, Canada

Collaborators This paper was based on the country work and analyses in conjunction with a workshop conducted in Naivasha, Kenya, 27-30 November 2018. The Countdown to 2030 collaboration for Eastern and Southern Africa is led by African Population and Health Research Centre and involves academic institutions (Johns Hopkins University, University of Manitoba), the WHO and the UNICEF, and included participation from 14 countries in the subregion. Eswatini, Ethiopia and South Africa also participated in the project but were not able to compile the required data sets for the analysis in time. The following participants worked on data preparation and analyses in the workshop:Botswana: Mooketsi M. Molefi (University of Botswana), Judith Letebele (Ministry of Health), Balekane Sitibi (Ministry of Health); Burundi: Jean Marie Ntibazomumpa (Ministry of Health), Joël Nibogora (Ministry of Health), Prosper Niyongabo (National Institute of Public Health for Research and Training); Eritrea: Amanuel Kifle (Ministry of Health); Eswatini: Sibusiso Charles Mamba (Ministry of Health); Ethiopia: Wubegzier Mekonnen Ayele (Addis Ababa University); DR Congo: Espoir Bwenge Malembaka (Ecole Régionale de Santé Publique, Université Catholique de Bukavu, Bukavu), Robert Banywesize (South Kivu Provincial Health Division, Bukavu); Kenya: Anne Khasakhala (University of Nairobi), Anthony Ngugi (Aga Khan University), Helen Kiarie (Ministry of Health), Valeria Makory (Ministry of Health), Leonard Cosmas (WHO); Lesotho: Lebohang Rantsatsi (Ministry of Health); Malawi: Simeon Yosefe (Ministry of Health), Golden Chanansi (Ministry of Health), Kondwani Chavula (Save the children), Monica Patricia Malata (University of Malawi); Mozambique: Gerito Augusto (Instituto Superior De Ciencias De Saude (ISCISA), Cesarino Tivane (Ministry of Health), Catarina Barrula (Ministry of Health), Cláudio Muianga (WHO); Namibia: Ezekiel Muyenga KAMBONGI Ministry of Health), Matheus Shiindi Ministry 
of Health); Rwanda: Pacifique Mukashema (Ministry of Health), Ntawuyirusha Emmanuel (Ministry of Health); South Africa: Innocent Maposa (Wits School of Public Health), Mamothena Carol Mothupi (University of the Western Cape); South Sudan: Augustino Ting Mayai (The University of Juba/Sudd Institute), Victor Misaka (Ministry of Health), Edward Ladu (Ministry of Health); Tanzania: Josephine Shabani (Ifakara Health Institute), Dhamira Mongi (Ministry of Health), Prisca Jackson (Ministry of Health), David Edward Lenga (Ministry of Health), Daudi Simba (Muhimbili University of Health and Allied Sciences); Uganda: Geraldine Agiraembabazi (Makerere University), Paul Mubiri (Makerere University), Jimmy Ogwal (Ministry of Health), Stephen Akena Bwoye (Ministry of Health); Zambia: Elizabeth Mwauluka (Ministry of Health), Mbonyiwe Jojo (Ministry of Health), Choolwe Jacobs (University of Zambia, School of Public Health); Zimbabwe: Rugare Abigail Kangwende (Ministry of Health), Lloyd Machacha (Ministry of Health), Vasco Chikwasha (University of Zimbabwe).

Contributors AM and TB conceptualised the study and the methodology. TB wrote the first draft and $A M$ was involved in drafting the manuscript and for data analysis. SSJ, MKKM, TAP, CMT, GA, DYM, CD, KLS, CMF, KV, KPO, AA and BSP contributed to the overall conceptualisation, provided guidance on the methodology and critical review on the manuscript. The staff from institutions involved in the Countdown to 2030 collaboration for Eastern and Southern Africa contributed in data preparation and analysis. All the authors have been involved in editing the paper, read and approved the final version.

Funding The analysis workshop and interaction with countries were funded by the WHO through a grant from NORAD and the Countdown to 2030 for Women's, Children's and Adolescents' Health through a grant from the Bill and Melinda Gates foundation (OPP1148933)

Disclaimer This paper expresses the views of the authors and does not necessarily represent the official views of their respective institutions. The funders have no involvement in the study design, implementation or decision to submit the paper for publication.

Competing interests None declared.

Patient consent for publication Not required

Provenance and peer review Not commissioned; externally peer reviewed.

Data availability statement All data relevant to the study are included in the article or uploaded as supplementary information.

Open access This is an open access article distributed in accordance with the Creative Commons Attribution 4.0 Unported (CC BY 4.0) license, which permits others to copy, redistribute, remix, transform and build upon this work for any purpose, provided the original work is properly cited, a link to the licence is given, and indication of whether changes were made. See: https://creativecommons.org/ licenses/by/4.0/.

\section{ORCID iDs}

Abdoulaye Maïga http://orcid.org/0000-0002-0475-1106

Martin Kavao Mutua http://orcid.org/0000-0003-1643-9934

Candy Day http://orcid.org/0000-0002-7290-0855

Cheikh Mbacké Faye http://orcid.org/0000-0002-4028-0575

Agbessi Amouzou http://orcid.org/0000-0002-6262-3866

Ties Boerma http://orcid.org/0000-0001-9922-495X

\section{REFERENCES}

1. WHO. Framework and standards for country health information systems. 2nd edn. Geneva: World Health Organization, 2008: 63.

2. AbouZahr C, Boerma T. Health information systems: the foundations of public health. Bull World Health Organ 2005;83:578-83.

3. Mutale W, Chintu N, Amoroso C, et al. Improving health information systems for decision making across five sub-Saharan African countries: implementation strategies from the African health Initiative. BMC Health Serv Res 2013;13:S9.

4. Etamesor S, Ottih C, Salihu IN, et al. Data for decision making: using a dashboard to strengthen routine immunisation in Nigeria. BMJ Glob Health 2018;3:e000807.

5. Braa J, Heywood A, Sahay S. Improving quality and use of data through data-use workshops: Zanzibar, United Republic of Tanzania Bull World Health Organ 2012;90:379-84.

6. Open Health News. District health information system 2 (DHIS2): open health news, 2018. Available: http://www.openhealthnews. com/resources/district-health-information-system-2-dhis2 [Accessed 21 Dec 2018].
7. Bhattacharyya S, Berhanu D, Taddesse N, et al. District decisionmaking for health in low-income settings: a case study of the potential of public and private sector data in India and Ethiopia. Health Policy Plan 2016;31(suppl 2):ii25-34.

8. WHO. Analysis and use of health facility data: guidance for national and district planners and managers, 2019: 105

9. Burton A, Monasch R, Lautenbach B, et al. WHO and UNICEF estimates of national infant immunization coverage: methods and processes. Bull World Health Organ 2009;87:535-41.

10. Ronveaux O, Rickert D, Hadler S, et al. The immunization data quality audit: verifying the quality and consistency of immunization monitoring systems. Bull World Health Organ 2005;83:503-10.

11. Gutreuter S, Igumbor E, Wabiri N, et al. Improving estimates of district HIV prevalence and burden in South Africa using small area estimation techniques. PLoS One 2019;14:e0212445.

12. Dunkle SE, Wallace AS, MacNeil A, et al. Limitations of using administratively reported immunization data for monitoring routine immunization system performance in Nigeria. $J$ Infect Dis 2014;210(suppl 1):S523-30.

13. Gething PW, Noor AM, Gikandi PW, et al. Improving imperfect data from health management information systems in Africa using SpaceTime Geostatistics. PLoS Med 2006;3:e0030271.

14. Gimbel S, Micek M, Lambdin B, et al. An assessment of routine primary care health information system data quality in Sofala Province, Mozambique. Popul Health Metr 2011;9:1-9.

15. Lim SS, Stein DB, Charrow A, et al. Tracking progress towards universal childhood immunisation and the impact of global initiatives: a systematic analysis of three-dose diphtheria, tetanus, and pertussis immunisation coverage. Lancet 2008;372:2031-46.

16. Mphatswe W, Mate KS, Bennett B, et al. Improving public health information: a data quality intervention in KwaZulu-Natal, South Africa. Bull World Health Organ 2012;90:176-82.

17. Venkateswaran M, Mørkrid K, Abu Khader K, et al. Comparing individual-level clinical data from antenatal records with routine health information systems indicators for antenatal care in the West bank: a cross-sectional study. PLoS One 2018;13:e0207813.

18. Chilundo B, Sundby J, Aanestad M. Analysing the quality of routine malaria data in Mozambique. Malar J 2004;3:3-11.

19. Maina I, Wanjala P, Soti $D$, et al. Using health-facility data to assess subnational coverage of maternal and child health indicators, Kenya. Bull World Health Organ 2017;95:683-94.

20. Githinji S, Oyando R, Malinga J, et al. Completeness of malaria indicator data reporting via the district health information software 2 in Kenya, 2011-2015. Malar J 2017;16:1-11.

21. Kiberu VM, Matovu JKB, Makumbi F, et al. Strengthening districtbased health reporting through the district health management information software system: the Ugandan experience. BMC Med Inform Decis Mak 2014;14:1-9.

22. WHO. Data quality review: a toolkit for facility data quality assessment. Module 2. Desk review of data quality. World Health Organization, 2017: 48.

23. Iglewicz B, Hoaglin DC. How to detect and handle outliers. Milwaukee, Wisconsin: American Society for Quality Control, 1993: 85.

24. United Nations. World population prospects 2019, online edition. New York: United Nations, Department of Economic and Social Affairs, Population Division, 2019.

25. Bissonnette L, Wilson K, Bell S, et al. Neighbourhoods and potential access to health care: the role of spatial and aspatial factors. Health Place 2012;18:841-53.

26. Murray CJL, Shengelia B, Gupta N, et al. Validity of reported vaccination coverage in 45 countries. Lancet 2003;362:1022-7.

27. Kumalija CJ, Perera S, Masanja $\mathrm{H}$, et al. Regional differences in intervention coverage and health system strength in Tanzania. PLoS One 2015;10:e0142066

28. Tashobya Kirunga C, Ssengooba F, Nabyonga-Orem J, et al. A critique of the Uganda district league table using a normative health system performance assessment framework. BMC Health Services Research 2018;18:1-17.

29. Mosser JF, Gagne-Maynard W, Rao PC, et al. Mapping diphtheriapertussis-tetanus vaccine coverage in Africa, 2000-2016: a spatial and temporal modelling study. Lancet 2019;393:1843-55.

30. Hotchkiss D, Diana M, Foreit K. How can routine health information systems improve health systems functioning in low-resource settings? assessing the evidence base. Chapell Hill: Measure Evaluation, 2012: 43

31. Wagenaar BH, Gimbel S, Hoek R, et al. Effects of a health information system data quality intervention on concordance in Mozambique: time-series analyses from 2009-2012. Popul Health Metr 2015:13:2-5. 
32. Dolan SB, Carnahan E, Shearer JC, et al. Redefining vaccination coverage and timeliness measures using electronic immunization registry data in low- and middle-income countries. Vaccine 2019;37:1859-67.

33. Aqil A, Lippeveld T, Hozumi D. PRISM framework: a paradigm shift for designing, strengthening and evaluating routine health information systems. Health Policy Plan 2009;24:217-28.
34. Nutley T, Reynolds HW. Improving the use of health data for health system strengthening. Glob Health Action 2013;6:20001-10.

35. Lippeveld T. Routine health facility and community information systems: creating an information use culture. Glob Health Sci Pract 2017;5:338-40. 